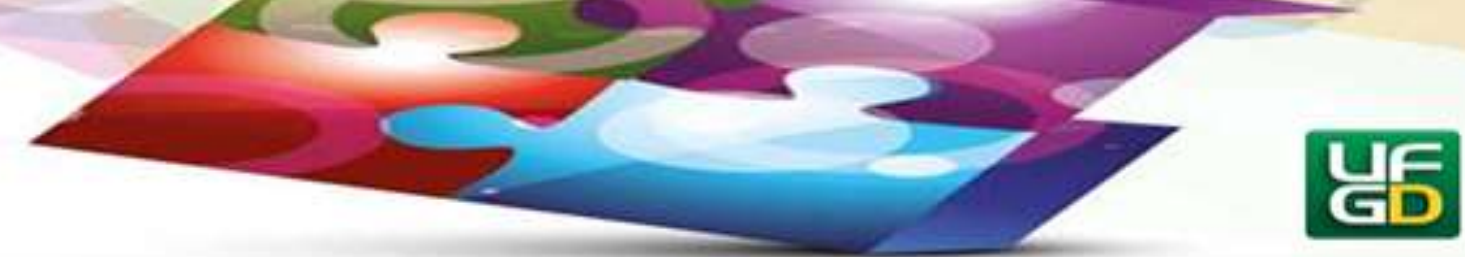

\title{
“NÃO SEJA BURRO”: VARIAÇÃO LINGUÍSTICA, LETRAMENTO E REPRESENTAÇÕES SOBRE A LÍNGUA PORTUGUESA
}

\section{“NO SEA BURRO”: VARIACIÓN LINGÜIISTICA, LETRAS Y REPRESENTACIONES SOBRE LA LENGUA PORTUGUÉS}

Marina Oliveira BARBOZA ${ }^{1}$

Resumo: O presente artigo tem por objetivo discutir questões acerca das variantes linguísticas e como estão concebidas no imaginário social. Desta forma, pretende-se identificar como são vistas pela população em geral e por professores do ensino básico. Tem-se a concepção geral de que anos de escola são proporcionais ao grau de letramento e performance na comunicação social (Kleiman, 1995), contudo observa-se que a escola não consegue abarcar, satisfatoriamente, as práticas sociais de uso da linguagem que são diversas e exigem do indivíduo mais que um conhecimento padrão e estrutural da língua falada ou escrita. Surgem os estereótipos atribuídos àqueles que não dão conta de uma língua que ser quer pura e imutável. Para as reflexões analisaremos o vídeo da youtuber Marcela Tavares "não seja burro", bem como os comentários feitos pelos internautas, tendo em vista que são representativos do pensamento comum sobre a língua. As reflexões serão norteadas pela perspectiva teórica de Bortoni-Ricardo (1995; 2003); Kleiman (1995); Signorini (1995); Street (2014); Mattos e Silva (2004) dentre outros.

Palavras-chave: Letramento. Variação linguística. Preconceito linguístico.

Resumen: Este artículo tiene como objetivo discutir cuestiones sobre variantes lingüísticas y cómo se conciben en la imaginación social. De esta forma, se pretende identificar cómo son percibidos por la población en general y por los docentes de educación básica. Existe una concepción general de que los años escolares son proporcionales al nivel de alfabetización y desempeño en la comunicación social (Kleiman, 1995), sin embargo se observa que la escuela no puede abarcar satisfactoriamente las prácticas sociales de uso del lenguaje que son diversos y requieren del individuo más que un conocimiento estándar y estructural del lenguaje hablado o escrito. Surgen los estereotipos atribuidos a quienes no pueden hacer frente a un lenguaje que quiere ser puro e inmutable. Para las reflexiones analizaremos el video de la youtuber Marcela Tavares "no seas estúpido", así como los comentarios que hacen los internautas, considerando que son representativos del pensamiento común sobre el idioma. Las reflexiones estarán guiadas por la perspectiva teórica de Bortoni-Ricardo (1995; 2003); Kleiman (1995); Signorini (1995); Street (2014); Mattos y Silva (2004) entre otros.

\footnotetext{
${ }^{1}$ Universidade Estadual de Londrina- UEL. E-mail: marinaleib@ hotmail.com 


\section{MORIZONTES - REVISTA DE EDUCAÇÃO}

Palabras-clave: Alfabetización. Variación lingüística. Prejuicio lingüístico.

\section{Introdução}

A escola sempre esteve presente ao longo da história como o lócus de saber e conhecimento e por muito tempo foi o espaço de privilégio de algumas classes sociais que tinham permissão para adentrar nesse campo. A escola é, prioritariamente, o espaço onde se adquire o letramento para a vida social, aprende-se a ler, escrever, a língua de prestígio.

Contudo, este letramento está atrelado às concepções de saber que estão ligadas às formas de exercício de poder e controle. Indivíduos letrados são comumente tidos como aptos a circular em diversos espaços e a falar de um lugar, pois são tidos como civilizados e cognitivamente organizados, capazes de agir no mundo. Enquanto aqueles que não adentram o espaço escolar são estigmatizados pela sociedade que os posiciona em um lugar menor e não apenas isso, mas sua condição humana é reduzida à animalização muitas vezes, como no exemplo do vídeo que analisaremos neste texto. Não são estigmatizadas apenas as línguas, mas os sujeitos que falam determinadas línguas e/ou variedades são percebidos como inferiores.

\section{Letramento e algumas considerações sobre ensino de língua portuguesa}

Bagno (2015) observa que o preconceito linguístico está nitidamente correlacionado a percepção que se tem daqueles que vêm das camadas populares, tendo em vista que o mesmo não ocorre com aqueles que são pertencentes às camadas sociais mais privilegiadas.

Signorini (1995) destaca que o acesso à escola é socialmente valorizado e tem-se a crença que o sujeito que frequenta a escola certamente terá sucesso na vida:

\footnotetext{
A sobrevivência na escola é comumente vista como sinônimo de aquisição dos bens culturais de prestigio - "ser estudado" é ser "educado", "mais elevado" (...) da mesma forma, tanto o não-acesso à escola quanto o fracasso escolar são vistos como sinônimos de déficit desses mesmos bens culturais - não ser "estudado" é ser ignorante, é não "saber das coisas" e ao mesmo tempo, como déficit de recursos necessários à ação social de base discursiva - não ser "estudado" é não falar "direito", é estar sempre vulnerável diante da multiplicidade de situações e interlocutores do cotidiano e, consequentemente, estar sempre sujeito ao fracasso na consecução de objetivos próprios (SIGNORINI, 1995, p. 162)
} 


\section{HORIZONTES - REVISTA DE EDUCAÇÃOO}

A autora destaca que a concepção atual de progresso social e desenvolvimento econômico está associada às taxas de escolarização ou analfabetismo. Esse progresso está intimamente ligado às relações de poder, assim, destaca Kleiman (1995, p. 8) que o domínio de diferentes usos da escrita significa acesso à mundos públicos e institucionalizados, como a mídia, o mundo da burocracia, etc.

Ser letrado e não apenas escolarizado pode garantir ao sujeito maior possibilidade de movimentação nos espaços sociais, bem como a possibilidade de dizer de um lugar historicamente determinado. Aos "iletrados" não cabe essa mesma posição visto que são marginalizados e/ou estigmatizados pela sociedade. Kleiman destaca que os estudos sobre letramento têm um foco amplo centrado nas diversas esferas da vida social e não apenas na escolar. Desse modo, estuda além das mudanças sócio históricas, a dominância e padronização de uma variante da linguagem. A variante padrão tornou-se sinônimo de língua, de modo que outras variantes ficam à margem.

O domínio da variante padrão não garante, contudo que o usuário consiga transitar de modo competente em todas as esferas sociais, visto que algumas esferas exigem bem mais que um conhecimento linguístico, mas sim um conhecimento empírico e de aspectos culturais e interacionais.

Paralelamente ao conceito de letramento como habilidade neutra, técnica e centrada no indivíduo está o conceito de "bom falante da língua portuguesa", ou seja, aquele que domina a estrutura linguística, diga-se a gramática da norma padrão e todos os aspectos codificantes da língua. Desse modo, a fuga dessa perspectiva de língua não é bem vista pela sociedade em geral. As variações da língua são consideradas como "erro" e os indivíduos que usam essas variantes são considerados como subescolarizados sendo estigmatizados principalmente quando usam a modalidade oral.

Sabemos, contudo, que apenas a aquisição de uma língua não garante ao falante competência comunicativa. Existem diversos fatores sociais, aspectos interacionais, culturais e comunicativos que podem interferir na atuação desse falante. 


\section{MORIZONTES - REVISTA DE EDUCAÇÃO}

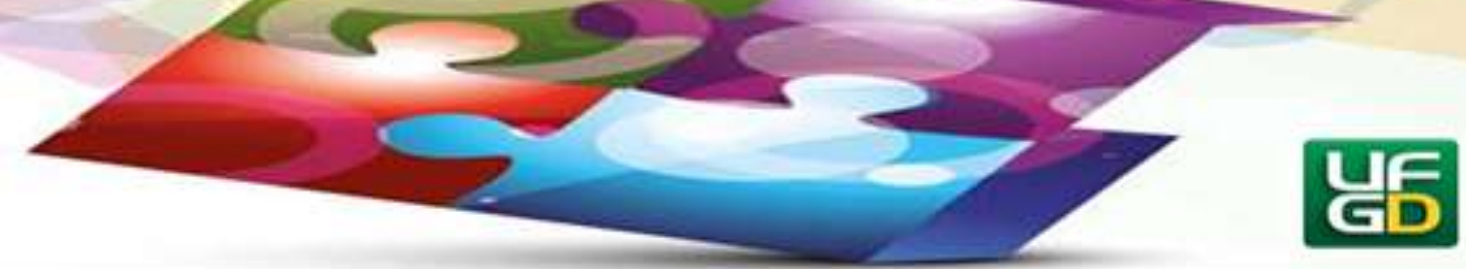

Signorini (1995, p. 171) em citação a Gumperz (1982) apresenta o conceito de flexibilidade comunicativa, que é "a habilidade necessária para se interagir satisfatoriamente com desconhecidos (sem experiência comum) oriundos de horizontes sócio e etnoculturais diversos". São sinais e pistas contextualizadoras empiricamente detectáveis e que segundo Gumperz não se adquire na escola ou por meio de leitura, já que são dados culturalmente, ou seja, fazem parte das redes de relações interpessoais e dependem de letramento em sentido mais amplo que apenas habilidades técnicas.

Street (2014) enfatiza a multiplicidade das práticas letradas em oposição à perspectiva autônoma orientada por habilidades. Para o autor a relação entre língua escrita e língua oral difere segundo o contexto. Esses contextos estão envoltos em práticas de letramento empíricas, bem como em preconcepções ideológicas que os sustentam.

Ao trazermos o conceito de letramento para o aprendizado da língua portuguesa, considerando-se as variedades da língua, assim como as variações lexicais, fonológicas, morfológicas queremos destacar a necessidade de conceber o aprendizado da língua não apenas como habilidade técnica e conhecimento estrutural e taxonômico da língua. Aprender uma língua na perspectiva do letramento envolve bem mais que saber ler, escrever ou conhecer a gramática de uma língua.

Ser falante de uma língua é estar historicamente e ideologicamente situado no seu tempo e espaço. Esse sujeito precisa dar conta da multiplicidade de situações e usos da linguagem, deve considerar além da adequação da língua nos diversos espaços, os veículos utilizados bem como as novas formas de comunicação tecnológicas do mundo globalizado.

Um falante historicamente situado sofre interferências de seu meio em muitos aspectos sejam eles linguístico-discursivos, sociais, ideológicos, de variação da língua e principalmente de crenças e atitudes diante do que acredita ser a língua "bem falada". Mattos e Silva (2004) argumentam que tendo em vista a amplitude territorial e heterogeneidade cultural, o Brasil é inegavelmente a nação da diversidade. Desse modo, “a língua portuguesa no Brasil, impossível de ser de outra forma, reflete isso, apesar de uma visão redutora insistir na "espantosa", "notável”, "esplêndida”, "apreciável” unidade do português do Brasil” (MATTOS E SILVA, 2004, p. 12). 


\section{MORIZONTES - REVISTA DE EDUCAÇÃO}

É com essa concepção de língua que a maioria das pessoas pertencentes as diversas classes sociais, julgam a língua portuguesa, como única, imutável e invariável. Muito dessa concepção é parte de um sistema ideológico advindo do período de colonização e de políticas linguísticas de negação ou anulação de outras línguas e falares diferentes do que se quer impor no país.

\section{Ensino e aprendizagem de língua portuguesa e variação linguística}

Segundo Mattos e Silva (2004) há duas atitudes polares em relação à língua, uma é aquela "dos que cobram a aplicação de uma norma obsoleta, idealizada por uma tradição cultural dominante, e a outra dos que encaram realisticamente a diversidade linguística do Brasil” (MATTOS e SILVA, 2004, p. 11).

Sabe-se que na história de colonização do país houve políticas linguísticas que favoreceram a disseminação de concepções de língua que temos hoje. (MARTINS, KNAPP e SALES, 2016, p. 315) destacam que essas políticas tiveram por objetivo negar a diversidade linguística e impor a língua portuguesa como a nacional e oficial. Assim, desde o século XVIII, o Marquês de Pombal intervém por meio de um decreto que proíbe o uso de qualquer outra língua que não seja o português. A partir de então, afirmam os autores que as línguas indígenas são excluídas e com elas os saberes que são adquiridos por meio da oralidade desses povos. A língua portuguesa passa a fazer parte do currículo escolar a partir do século XIX e com isso toda uma metodologia e uma maneira de conceber a língua portuguesa e seu ensino.

MATTOS e SILVA (2004) destacam que a forma como foi desenvolvida a escolarização no Brasil é fator relevante. A autora pontua que a história de colonização do Brasil, por europeus, africanos, bem como pela presença dos indígenas que aqui estavam não permite, como quer o ideal homogeneizador da língua e da cultura, afirmar que nossa língua é homogênea. Há um "português brasileiro heterogêneo geograficamente, mas sobretudo na escala social" afirma a autora.

Enfatiza que no século XIX ocorre uma divisão acirrada que resultou na "diglossia" atual colocando-se em dois polos, de um lado, uns poucos portadores de uma língua padrão lusitana primeiramente, depois um padrão culto brasileiro e no outro polo a massa de iletrados 


\section{MORIZONTES - REVISTA DE EDUCAÇÃO}

ou precariamente letrados. Desse modo, a pesquisadora diz que surge o policiamento gramatical como preocupação da elite brasileira. Esse policiamento impede que se dê atenção às variantes da língua. Destaca Matos e Silva que a escola brasileira não dá conta da transmissão de um padrão linguístico de tradição normativa, visto que há tanto uma heterogeneidade de estudantes, quanto de professores que, provenientes de diversas camadas sociais, trazem variantes linguísticas que se afastam do padrão normativo, cujo modelo é o português padrão idealizado e originário do português europeu.

FARACO (2008) diz que não há uma dicotomia entre língua e suas variedades, pois “empiricamente, a língua é o próprio conjunto das variedades”, logo tem-se uma realidade sócio linguística heterogênea. Observa ainda que a língua é uma entidade cultural e política, ou seja, ela não é definida por critérios puramente linguísticos, mas por critérios políticos e culturais. Mattos e Silva (2004) já apontava para essa perspectiva quando analisa as orientações metodológicas contidas nas Diretrizes da Comissão Nacional MEC em 1986. As Diretrizes reconhecem a necessidade de se considerar as variantes de alunos advindos de diversas camadas sociais e culturais, mas ao mesmo tempo o foco central é a exigência da norma padrão, propondo assim um ensino de "língua de cultura", mas que segundo a autora refere-se a cultura em sentido estrito, ou seja, refere-se aos valores da cultura dominante, sendo essa uma posição política e ideológica. A cultura trazida das comunidades menos prestigiadas é invisibilizada na escola.

Não há um entendimento na escola o modo de como ensinar as variedades da língua, pois não há um reconhecimento dessas variedades. Possenti (2002) afirma que,

Todas as línguas mudam, de maneira que não há razão de ordem científica para exigir que alunos dominem formas arcaicas que nunca ouvem e que pouco encontram, mesmo nos textos escritos mais correntes. Gastar um tempo enorme com regências e colocações inusitadas é, a rigor, inútil. (...) haveria muitas vantagens no ensino se a escola tivesse como padrão ideal de língua a ser atingido pelos alunos algo como a escrita dos jornais ou dos textos científicos, ao invés de ter como modelo a literatura antiga. (POSSENTI, 2002, p.35-36)

O autor argumenta que a aprendizagem deve ocorrer por meio de práticas efetivas, significativas e contextualizadas. Nessa perspectiva argumenta também Geraldi (2002) que toda metodologia de ensino traz em si uma opção política. O autor diz que é preciso pensar não 


\section{MORIZONTES - REVISTA DE EDUCAÇÃO}

apenas no como ensinar e quando ensinar, mas principalmente pensar - "para que ensinamos o que ensinamos? E para que as crianças aprendem o que aprendem". Isso envolve conforme o autor uma concepção de linguagem.

Desse modo, defende uma concepção de linguagem pautada na situação concreta de interação, na qual o falante se constitui nas relações sociais como sujeito, "no ensino da língua, nessa perspectiva, é muito mais importante estudar as relações que se constituem entre os sujeitos no momento em que falam do que simplesmente estabelecer classificações e denominar os tipos de sentença" (GERALDI, 2002, p. 42).

As situações concretas de uso da língua (gem) trazem em si as inúmeras possibilidades do dizer, visto que estão inseridas em contextos sócio-históricos em continuo movimento. A língua não se prende às rígidas regras, antes obedece ao seu entorno, à sua história, ao seu contexto e aos seus falantes, ou seja, a variação linguística é inerente à língua em uso. Faraco (2008) defende que

os falantes variam sistemática (e não aleatoriamente) sua expressão e tomam como baliza não um padrão absoluto de correção, mas critérios de adequação às circunstâncias. Nesse sentido, os fenômenos linguísticos não são relativos, mas relativos às circunstâncias (FARACO, 2008, p. 166). Grifo nosso.

O autor argumenta que a ideologia da língua homogênea condena a variação e usa como régua as prescrições da gramática da norma curta $^{2}$. Em relação ao "erro" Bortoni-Ricardo (2006, p. 268) enfatiza que os professores-alfabetizadores precisam fazer uma distinção entre "problemas na escrita e na leitura que decorrem da interferência de regras fonológicas variáveis e outros que se explicam simplesmente pela falta de familiaridade do alfabetizando com as convenções da língua escrita”. Desse modo, diz a autora que para a sociolinguística o que a sociedade tacha como erro é tão somente uma inadequação frente às expectativas dos ouvintes. A teoria sociolinguística, destaca Bortoni, "substitui a noção tradicional de erro pela noção de diferenças entre variedades ou entre estilos” p. 272.

\footnotetext{
${ }^{2}$ Norma curta termo cunhado por Faraco (2008) e que segundo o autor, diz respeito a um conjunto de preceitos dogmáticos e normativos saídos do purismo exacerbado advindo das concepções sobre a língua desde o século XIX até o presente. 


\section{MORIZONTES - REVISTA DE EDUCAÇÃO}

Em análise ao binômio erro-correção no ensino de línguas Assis-Peterson (2009) diz que a aprendizagem de uma língua é um fenômeno multifacetado e que na visão purista, a língua se confunde com a norma padrão ou modelo ideal do falante nativo e tudo que fuja desse padrão é considerado erro ou desvio, formas que não teriam o direito à existência.

Contudo, o objetivo de uma língua é a comunicação e interação entre seus falantes, é estar no mundo de modo a agir sobre o mesmo por meio da linguagem, ou seja, para além do erro é preciso observar uma competência comunicativa mais abrangente como a sugerida em Block (2003), para o autor é preciso,

[...] mostrar uma preocupação não só com a comunicação referencial a serviço da troca de informação, mas também com a comunicação interacional e interpessoal a serviço da construção social da identidade, afiliação ao grupo, solidariedade, apoio, confiança, etc. (BLOCK, 2003, p. 64 apud ASSIS-PETERSON, 2009, p. 162)

O erro deve ser visto e corrigido, mas dentro dos parâmetros que não tirem do falante o direito que tem de ser sujeito de sua língua e de sua identidade. Bortoni-Ricardo (2006), diz que não há transgressão ou erro na fala, mas diferenças entre maneiras possíveis de se falar. Ao contrário, na ortografia há uma transgressão, pois há um código convencionado e prescrito destaca a autora,

[...] é por isso que a Sociolinguística abomina referir-se a erros quando se trata de fala, considerando-os todavia, quando são transgressões ortográficas [...] considerar uma transgressão à ortografia como erro não significa considerá-la como uma deficiência do aluno que dê ensejo a críticas ou a um tratamento que o deixe humilhado(BORTONIRICARDO, 2006, p. 274).

Eis o ponto central no ensino ou na abordagem da língua, ou seja, o modo como as pessoas são posicionadas na escala social de valores e bens simbólicos por conta de seu comportamento linguístico. Frente à essa polaridade da língua padrão como sinônimo de "melhor falar" e a língua real, em uso, falada por todos os falantes, estão as concepções de língua baseadas em crenças sobre o que significa para as pessoas falar de determinada forma e não de outra. Essas crenças levam a atitudes sociais não apenas de depreciação da língua falada por determinados grupos sociais, como também leva a deslegitimação dos discursos produzidos por esses sujeitos na sociedade, bem como a tratamentos desiguais em vista da língua falada. 


\section{HORIZONTES - REVISTA DE EDUCAÇÃO}

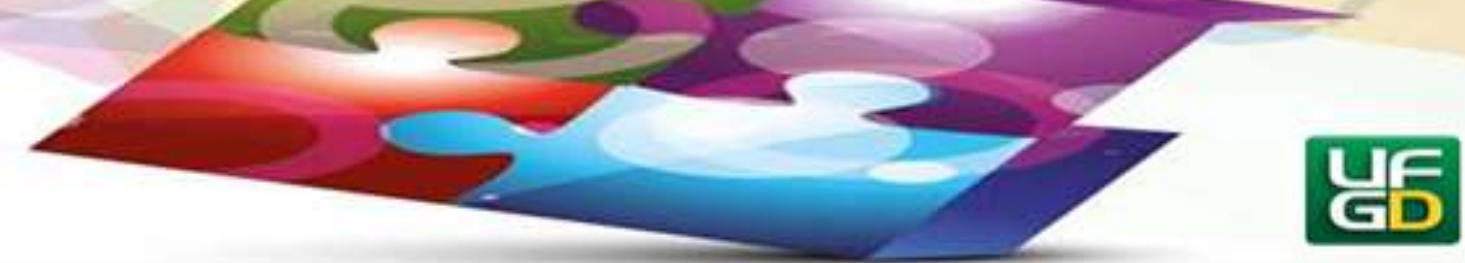

“Não seja burro": crenças e atitudes que levam ao preconceito linguístico e social

A língua sempre foi arena de conflitos sociais e ideológicos como bem destaca Bakhtin (1985). Neste tópico analisaremos os discursos sobre a gramática do português apresentados pela youtuber Marcela Tavares. As séries de vídeos intitulados: “Não seja burro! ” trazem ao lado do aspecto cômico, toda a representação do preconceito contra quem utiliza variantes do português.

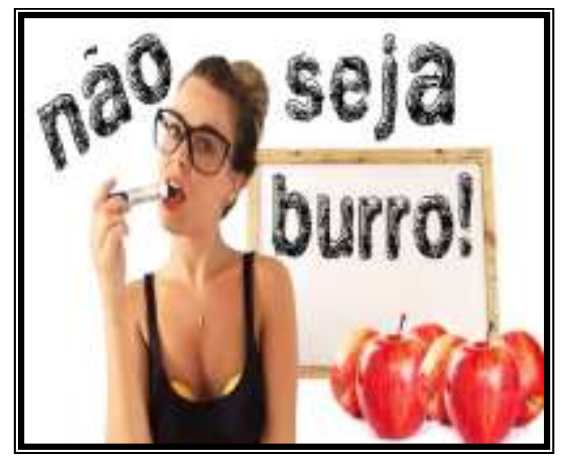

Aprenda a escrever/falar com a Tia (SQN) Marcela Tavares e sejA uma pessoa maIs feliz!

As correções são feitas sempre em depreciação aos sujeitos falantes das variantes que são apontadas pela youtuber como "erros graves". Como já dizia Bagno (2007), nada na língua é por acaso. A postura da youtuber e a forma como as variantes são corrigidas no vídeo são representativas da insatisfação e da agressividade de uma elite dominante que acredita numa língua homogênea e restrita. Por trás dessa violência simbólica estão os discursos que ecoam desde o período colonial. Esses discursos aparecem em falas do tipo "português é difícil", a performatividade dessa afirmação é tamanha que as pessoas no geral acreditam não saber o português. Bagno (2015) lembra que este é um dos mitos sobre a língua portuguesa. O autor diz que essa afirmativa serve mais para manter o status quo das classes sociais privilegiadas. Não se pode impedir ninguém de falar, mas pode-se, então, criar uma língua inacessível e dessa forma destituir os sujeitos dos possíveis lugares que poderiam ocupar na sociedade. Assim age o poder hegemônico.

Gnerre (2009, p. 6-7) destaca que "uma variedade linguística "vale” o que "valem" seus falantes, isto é, vale como reflexo do poder e da autoridade que eles têm nas relações 


\section{MORIZONTES - REVISTA DE EDUCAÇÃOO}

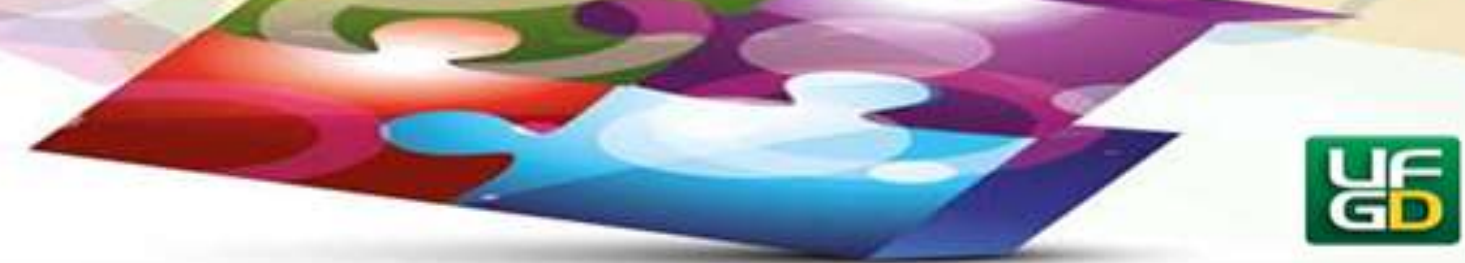

econômicas e sociais". Assim, as pérolas de Marcela Tavares tais como "Ancioso não se escreve com C de cavalo, sua anta! ”, não são, necessariamente, dirigidas àqueles de classes mais abastadas, visto que se acredita que erros ortográficos não possam ser cometidos por alguém que tenha posses, pois os erros pertencem necessariamente ou estão mais presentes nas classes menos abastadas, ou seja, ter posses está intimamente ligado a ter cultura, saber legitimado, poder linguístico.

A crença de que "falar errado" ou "escrever errado" é algo terrível leva as pessoas a terem atitudes preconceituosas em relação às pessoas. A capacidade cognitiva da pessoa é posta à prova, bem como sua competência de atuação nos espaços sociais. O vídeo de Marcela traz muitas crenças sobre a língua que estão no imaginário das pessoas:

1. "Em pleno século XXI ainda tem gente que escreve e fala errado... eu não admito isso";

2. "Você acha que é manero, fala e escreve errado?".

3. "Você acha que você vai ter amigos... você acha que você vai conseguir conquistar o mundo falando errado, é obvio que não".

4. "Aurélio fica puto quando lê isso aí".

5. "Não fazem dois dias, oh imbecil, faiz dois dias...faiz ... faiz..."

6. "Mim não é sujeito... não é... não é..., mim não faiz nada... mim não pega nada e você não é índio e hoje eu acho que até o índio já sabe que mim não conjuga verbo, é prá eu (palavrão), não é pra mim".

7. "Ancioso não se escreve com C de cavalo, sua anta!"

Na perspectiva discursiva há nos trechos acima citados toda uma ideologia materializada nas escolhas lexicais utilizadas para "corrigir o português". No excerto 1 temos a ideia de "falante do século XXI", que logicamente, deve falar corretamente, logo quem não possui esse falar "correto", pertence ao passado, é retrógrado. Utilizando uma das variantes do português a youtuber tenta intimidar aqueles que utilizam outras variantes da língua: "você acha manero, fala e escreve errado? (2). O sujeito falante dessa variante é considerado incapaz e pouco interessante e se não falar "correto" será isolado socialmente: "você acha que vai ter amigos"? (3) E não terá habilidades para "conquistar o mundo". A agressividade contra os falantes chega a tal ponto que são chamados de "imbecil", "anta" (5). Ao corrigir a palavra ansioso escrita com C, a atriz sugere uma analogia entre falantes que escrevem "ansioso" com C e o animal cavalo (7), novamente. Há uma animalização e transformação desses falantes em sujeitos grotescos e incapazes e, portanto, não podem ter acesso aos mesmos espaços daqueles que 


\section{MORIZONTES - REVISTA DE EDUCAÇÃO}

dominam o português. A youtuber não leva em consideração os problemas ortográficos em virtude de interferências na pronúncia, na produção escrita dos problemas decorrentes do caráter arbitrário das convenções ortográficas como bem nos alerta Bortoni-Ricardo.

A youtuber vai mais além nas provocações preconceituosas quanto ao uso da língua. Como bem destaca Bakhtin há responsividade na língua (gem). Ao mencionar os indígenas, ela traz do passado colonial que ainda ecoa na linguagem e nos discursos todo um leque de preconceitos contra essa população tida como primitiva, selvagem e incapaz de aprender uma língua: "e você não é índio. E pondera, "e hoje eu acho que até o índio já sabe que mim não conjuga verbo". Contudo, o uso do conectivo "até" deixa claro que "esse índio de hoje", ainda é considerado subalterno. Não são simples chistes, mas discursos que traduzem uma ideologia sectária de classe. O caráter humorístico faz com que as pessoas pouco percebam a seriedade da questão linguística e social.

Surpreendente é o número de seguidores que a youtuber possui. São cerca de 540 mil inscritos em seu canal e seus vídeos tem mais de 300 milhões de visualizações. Também recebe apoio de professores de língua portuguesa como nos exemplos a seguir: "Você lava minha alma!!! 23 anos de sala de aula dando aula de Lingua Portuguesa! Parabéns”! E de alunos: "você é melhor do que minha professora"; "uma aula de português de graça e o vídeo ainda recebe deslike!".

Pode-se perceber que há uma cultura massificada que acredita em um português puro, intocável. Aliás, acreditam que essa demonstração bizarra de correção de língua é plausível de ser considerada uma aula de língua portuguesa.

Sobre erro e correção, Assis-Peterson $(2009$, p. 166) diz que quando se corrige, o que está em jogo na correção não são apenas os aspectos linguísticos, mas também a correção da imagem do outro, coloca-se em jogo a negociação de identidade. Nesse sentido, os muitos "erros" em português na verdade são marcas de identidade, regional ou social. Considerandose uma pedagogia dialógica a autora diz:

Nessa visão, os textos que os alunos falam e escrevem não devem ser considerados apenas como exemplos de instâncias de enunciação fonológica, gramatical ou lexical, mas como enunciados situados social e culturalmente, contribuindo para a construção de subjetividades. Acolher o erro é dialogar com a alteridade. (ASSIS-PETERSON, 2009, p. 167) 


\section{MORIZONTES - REVISTA DE EDUCAÇÃO}

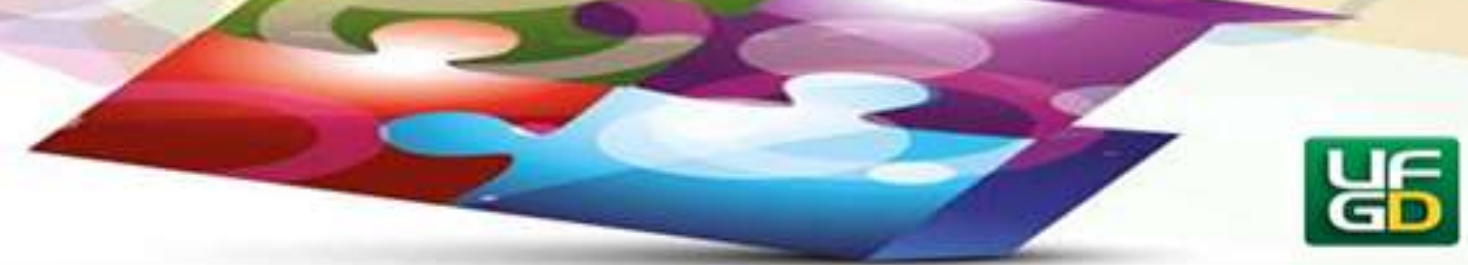

Matos e Silva (2004), alertam que se deve fugir de posições extremistas que defendem o purismo linguístico ou posições de que tudo ou qualquer uso da língua é válido em qualquer circunstância. Sugere a autora que o professor deve levar o aluno a tornar-se sujeito de sua fala e de sua língua, dando-lhe a oportunidade de conhecer a língua nas suas diversas formas de uso e de manifestação para que possa escolher conscientemente qual forma e em quais situações determinadas usos são mais adequados ou não.

A língua não pertence a alguns poucos privilegiados, mesmo que o queiram, "a língua foge e escapa por ruelas e becos os mais diversos". A língua não se deixa fixar no tempo ou no espaço, antes ela obedece às evoluções do tempo, do espaço, dos nomes, da história e se dobra, muda, continua, se revela, se reproduz, à revelia daqueles que a querem imutável, pura.

\section{Considerações}

A língua é bem mais que um amontoado de códigos a serem decifrados ou regras a serem seguidas em determinados contextos. As críticas não são como destaca Faraco sobre um "tudo pode" na língua como querem os extremistas e/ou guardiões da língua "certa". Há uma intencionalidade em não querer ouvir o que os especialistas (linguistas) querem dizer sobre a língua. Contudo, esse discurso agressivo contra a língua em uso toma proporções astronômicas quando invadem a grande mídia, pois é laboriosamente manipulado para persuadir as pessoas a acreditarem que realmente não sabem o português do país em que nasceram.

O professor de língua também não ocupa uma situação confortável, pois durante sua formação aprendeu que o ensino de língua portuguesa se baseia no ensino de gramática, e como dizer a ele e aos milhões de falantes que foram ensinados dessa forma, que gramática não é a língua, mas sim o manual de como a língua pode funcionar? A língua, como já dissemos, não é um amontoado de códigos ou taxonomias. A língua percorre contextos e precisa se adaptar a eles, seja no estilo, nos aspectos sócio-interacionais e isso não está na gramática pura. É preciso compreender como a língua (gem) funciona nos espaços de poder, nos espaços públicos, na responsividade, nos discursos, nos silêncios. Essa acomodação linguística às necessidades reais de uso, bem como a percepção de que a língua funciona como objeto de poder é que deveria 


\section{MORIZONTES - REVISTA DE EDUCAÇÃO}

ser o foco principal do ensino de língua portuguesa. Destacando que dissemos foco principal e não único. O estudo da metalinguagem tem sua validade desde que seja contextualizado e tenha como foco uma perspectiva contrastiva com a língua em uso, deixando de lado as concepções preconceituosas que em nada contribuem para um ensino reflexivo da língua.

O professor poderia propor aos alunos um ensino crítico da língua. Castilho (2000) sugere que o mais adequado seria a sensibilização do aluno frente à variabilidade linguística descondicionando-o de uma visão conteudista do ensino de língua portuguesa. Sugere atividades voltadas para observação dos fatos da linguagem de modo a preparar o aluno para uma mudança de ambiente, bem como para evitar preconceitos em relação a língua em uso (CASTILHO, 2000, p. 29).

Acreditamos que o professor tem um papel fundamental na desmistificação do que é o ensino de língua portuguesa, mas para isso precisa primeiro se libertar de seus próprios preconceitos sobre a língua. Para ensinar considerando as variedades é preciso reconhecer estas variedades em seu meio social e que ele mesmo é falante desses dialetos. É preciso conhecimento teórico sobre os últimos avanços e estudos sobre a língua. Do contrário o professor de língua portuguesa continuará repetindo o que aprendeu e, no seu caso, perpetuando ideias preconcebidas sobre a língua.

\section{Referências}

ASSIS-PETERSON, Ana Antônia de. Hippie ou Hype? Para refletir sobre o binômio errocorreção no ensino de línguas. In: MOTA, Kátia e SCHEYERL, Denise (Orgs.) Espaços Linguísticos: Resistências e expansões. EDUFBA, Salvador, 2009.

BAGNO, Marcos. Preconceito Linguístico. São Paulo: Parábola, 2015.

Nada na língua é por acaso: por uma pedagogia da variação linguística. São Paulo: Parábola, 2007.

BORTONI-RICARDO, Stella Maris. O estatuto do erro na língua oral e na língua escrita. In: GORSKI, Edair Maria; COELHO, Izete Lehmkuhl (orgs). Sociolinguística e ensino: contribuições para a formação do professor de língua. Florianópolis, Ed. UFSC, 2006.

Processos interativos em sala de aula e a pedagogia culturalmente sensível. Polifonia. EdUFMT, Cuiabá, nº 07, p.119-136. 


\section{MORIZONTES - REVISTA DE EDUCAÇÃO}

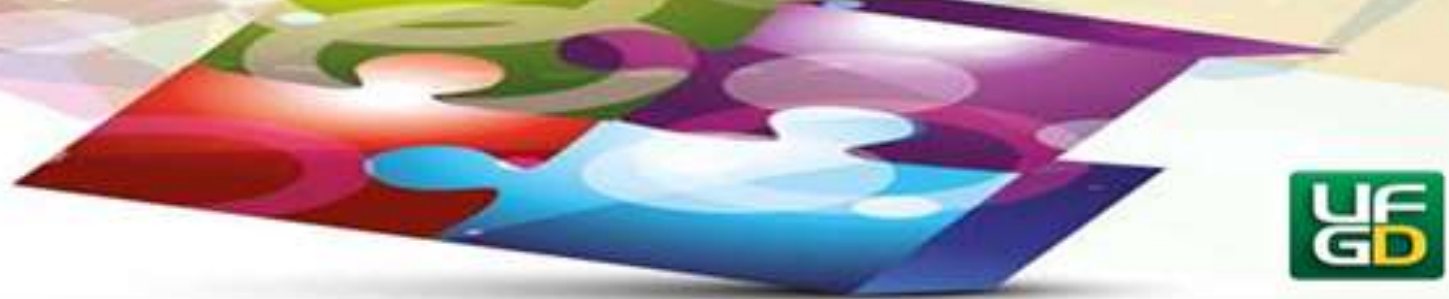

FARACO, Carlos Alberto. Norma Culta Brasileira: desatando alguns nós. São Paulo. Parábola, 2008.

GERALDI, João Wanderley. Concepções de Linguagem e Ensino de Português. In:

GERALDI, João Wanderley (Org.). O texto na sala de aula. São Paulo. Ática, 2002.

GNERRE, Maurizio. Linguagem, escrita e poder. São Paulo: Martins Fontes, 2009.

KLEIMAN Ângela. Os significados do letramento: uma nova perspectiva sobre a prática social da escrita. Campinas, SP: Mercado de Letras, 1995.

MARTINS, Andérbio Marcio Silva.; KNAPP, Cassio; SALES, Adriana. Políticas linguísticas na Licenciatura Intercultural Indígena - Teko Arandu. ReVEL, v. 14, n. 26, 2016. Disponível em: <http://www.revel.inf.br/pt/edicoes/?mode=anterior $>$. Acesso em julho de 2017.

MATOS e SILVA, Rosa Virgínia. O Português são dois, novas fronteiras, velhos problemas. São Paulo. Parábola, 2004. (p. 11-36; 128-151)

POSSENTI, Sírio. Sobre o Ensino de Português na Escola. In: WANDERLEY, Geraldi (Org.). O texto na sala de aula. São Paulo. Ática, 2002.

SIGNORINI, Inês. Letramento e (in)flexibilidade comunicativa. In: KLEIMAN, Ângela B (org.). Os significados do letramento: uma nova perspectiva sobre a prática social da escrita. Campinas, SP: Mercado de Letras, 1995.

STREET, Brian. LETRAMENTOS SOCIAIS - Abordagens críticas do letramento no desenvolvimento, na etnografia e na educação. Tradução: Marcos Bagno. Parábola, 2014.

TAVARES, Marcela. "Não seja burro"! Vídeo publicado em 11 de janeiro de 2016. Disponível em: 〈https://www.youtube.com/watch?v=Uy_OzzOdgXo $>$. Acesso em julho de 2017.

Enviado: $30 / 06 / 2020$

Aceito: $31 / 08 / 2020$ 